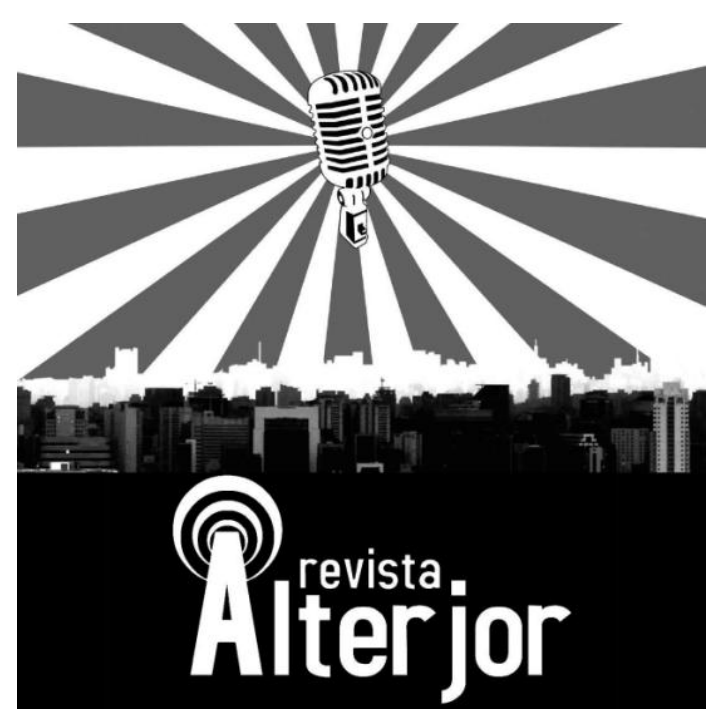

\title{
NO CLIMA DA COPA: UM BOLETIM DE RÁDIO E SEUS AMBIENTES COMUNICACIONAIS ${ }^{1}$
}

\author{
Elcio Cassola Padovez ${ }^{2}$ \\ José Eugenio de Oliveira Menezes ${ }^{3}$
}

RESUMO: Este trabalho problematiza como o boletim No Clima da Copa, desenvolvido pelo jornalista Elcio Padovez durante a Copa do Mundo da Rússia e veiculado pela emissora paulistana Rádio Gazeta entre junho e julho de 2018, foi gerado e compartilhado em ambientes comunicacionais. A partir das noções de ambiente comunicacional (Baitello Jr.), etnografia (Winkin) e cultura (Bystrina; Gebauer), mostra indícios de que o boletim, marcado pela postura etnográfica do repórter, envolveu os ouvintes em um ambiente comunicacional e mostrou as potencialidades das pesquisas acadêmicas e das produções jornalísticas quando gestadas no diálogo entre antropologia (postura etnográfica) e comunicação.

PALAVRAS-CHAVE: Cultura do Ouvir. Ambientes comunicacionais. Etnografia.

ABSTRACT: This work problematizes how the bulletin No Clima da Copa, developed by journalist Elcio Padovez during the World Cup in Russia and aired by São Paulo radio station Rádio Gazeta between June and July 2018, was generated and shared in communication environments. From the notions of communicational environment (Baitello Jr.), ethnography (Winkin) and culture (Bystrina; Gebauer), it shows evidence that the bulletin, marked by the reporter's ethnographic attitude, involved listeners in a communicational environment and showed the potential academic research and journalistic productions when generated in the dialogue between anthropology (ethnographic attitude) and communication.

KEYWORDS: Listening Culture. Communication environments. Ethnography. Radio. Russia World Cup.

\footnotetext{
${ }^{1}$ Trabalho apresentado no GP Comunicação e Esporte, no $43^{\circ}$ Encontro dos Grupos de Pesquisas em Comunicação, evento componente do $43^{\circ}$ Congresso Brasileiro de Ciências da Comunicação.

${ }^{2}$ Mestre em Comunicação pela Faculdade Cásper Líbero (FCL) e pesquisador dos grupos Cultura do Ouvir (FCL) e GEPECOM (EEFE - USP). E-mail: padovezelcio@gmail.com.

${ }^{3}$ Doutor em Ciências Comunicação pela Universidade de São Paulo (USP). Docente do Programa de Pósgraduação em Comunicação da Faculdade Cásper Líbero (FCL). Grupo de Pesquisa Comunicação e Cultura do Ouvir. E-mail: menezes.eugenio@gmail.com
}

Revista ALTERJOR

Grupo de Estudos Alterjor: Jornalismo Popular e Alternativo (ECA-USP)

Ano 10 Volume Ol Edição 23 Janeiro-Julho de 202l

Avenida Professor Lúcio Martins Rodrig̉ues, 443, Cidade Universitária, São Paulo, CEP: 05508-020 


\section{O SOM AO REDOR}

No início de 2018 eu me preparava para dois desafios em relação à Copa do Mundo da Rússia. O primeiro, acadêmico, no qual colocaria na prática os conhecimentos que havia cultivado durante os três primeiros semestres do mestrado, e que ao fim deste, em março de 2019, veio a se concretizar na dissertação Os símbolos na construção da Copa do Mundo de 2018.

O segundo seria profissional, já que, em paralelo às pesquisas de campo, continuei a exercer a função de jornalista e produzir materiais especiais sobre o torneio para o Estadão ${ }^{4}$ e, poucos dias antes da viagem, que começou em 6 de junho, recebi o convite da Rádio Gazeta para um desafio que nunca havia enfrentado: produzir um boletim de rádio diário sobre o megaevento esportivo.

O convite a um estudante da pós-graduação da Faculdade Cásper Líbero também fazia parte de um programa desenvolvido pela instituição para fortalecer os diálogos entre o conteúdo programático ensinado tanto na graduação quanto na pós e o trabalho prático dentro da área de comunicação. O diálogo entre a academia e o mercado é algo que considero essencial dentro da prática da comunicação e decidi aceitar. Após algumas reuniões e orientações técnicas da rádio, embarquei para a Rússia e dentre as atividades que desenvolveria no país, eu deveria produzir diariamente, por meio do gravador do celular, um boletim radiofônico, com duração entre quatro e oito minutos, que seria veiculado no programa Disparada no Esporte, apresentado pela jornalista Regiane Ritter de segunda à sexta-feira, das $11 \mathrm{~h}$ às $12 \mathrm{~h} 30$, e veiculado na Rádio Gazeta AM. Após a veiculação nesta frequência, cada episódio passava a ser disponibilizado em uma aba do site da Rádio Gazeta Online, acompanhado de uma breve descrição em texto e uma foto. A história da viagem e da cobertura pode ser acessada e ouvida ainda hoje ${ }^{4}$.

Durante 33 dias, gravei 30 boletins radiofônicos. Cada um deles abordou um aspecto da cultura russa, como a história, a alimentação, o esporte, as tradições e os rituais, além de narrar uma viagem na qual percorri mais de 41 mil km e passei por 9 das 11 cidades-sede da Copa do Mundo da Rússia.

\footnotetext{
4 Boletim disponível em: <http://www.radiogazetaonline.com.br/no-clima-da-copa/. >. Acesso em: 20 set. 2020.
} 


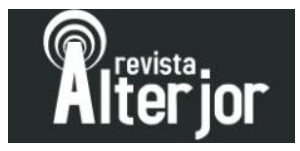

Em alguns momentos no presente texto, como percebe o leitor, alterei sua forma verbal para contemplar em primeira pessoa do singular o protagonista da elaboração dos boletins - Elcio Padovez - e em terceira pessoa os autores da análise desta experiência.

Este artigo tem como objetivo analisar, como, por meio do boletim No Clima da Copa, foram vivenciados e compartilhados ambientes comunicacionais por meio das ondas de uma rádio, seja de modo analógico ou digital.

Como referenciais teóricos dialogamos com a noção de ambiente comunicacional de Norval Baitello Jr, a postura etnográfica do pesquisador belga Yves Winkin, além do de cultura, na perspectiva dos pensadores da Universidade Livre de Berlim, como o semioticista tcheco Ivan Bystrina (1924-2004) e o filósofo alemão Gunter Gebauer.

\section{A comunicação começa no corpo que gera ambientes comunicacionais}

Antes de exemplificar como o boletim No Clima da Copa compartilhou ambientes comunicacionais a partir da Rússia para os ouvintes brasileiros da Rádio Gazeta Online, é necessário expor os conceitos de etnografia, que norteou importante parte do trabalho de campo, e o de cultura, a partir dos estudos de Ivan Bystrina (19242004) e Gunter Gebauer, além do de ambiente comunicacional, estudado pelo filósofo japonês Tetsuro Watsuji (1889-1960) e o pesquisador brasileiro Norval Baitello Jr.

No livro Antropologia da Paisagem (2006), Watsuji propõe que um ambiente comunicacional não é apenas o pano de fundo para uma troca de informações, mas uma atmosfera gerada pela disponibilidade dos seres (pessoas ou coisas), por sua intencionalidade de estabelecer vínculos (Watsuji, 2006, p. 77). Já para Baitello (2013), a palavra ambiente (em latim, ambi) é algo que existe entre dois lados e portanto, devemos entendê-la como um conceito espacial daquilo que nos cerca. É o nosso entorno e não é apenas o pano de fundo para uma troca de informações, mas uma atmosfera gerada pela disponibilidade dos seres (pessoas ou coisas) por sua intencionalidade de construir vínculos. Para que ele seja gerado, é preciso que haja um corpo, pois, segundo o comunicador e comunicólogo alemão Harry Pross, é nele que a comunicação começa e termina (PROSS,1991). A partir do que ele passa a chamar de comunicação primária, é 


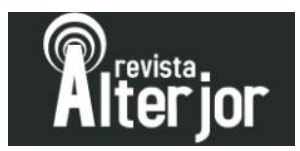

possível gerar ambientes, assim como ser gerados por eles. O homem interfere sobre os ambientes assim como sofre interferências deles.

A partir desta explicação inicial, pode-se desmembrar os ambientes a partir da comunicação. Uma dessas possibilidades é a geração de ambientes digitais, que para Baitello estão:

fora ou longe de nós. Portanto, o digital implica em quantidade e distância. Quando falarmos da geração de ambiente, vamos entender melhor o conceito de ambiente digital, que é um ambiente que quantifica e aponta coisas distantes. É um ambiente feito de algarismos (números), algoritmos e indicações. Por isso, nós falamos das telecomunicações, importantes para os ambientes de hoje, de comunicação de longa distância. $\mathrm{O}$ ambiente digital opera com vazios e com distâncias. Operar com o vazio significa operar com o nada (Baitello, 2013).

No caso deste artigo, trataremos da geração de ambientes digitais sonoros, feitos a partir da produção diária do boletim No Clima da Copa. Por meio da narração em primeira pessoa, a ideia do produto veiculado pela Rádio Gazeta foi de criar uma experiência para "transportar" o ouvinte para dentro da Rússia e da Copa do Mundo por meio da voz, mesmo que ele e o narrador estivessem a mais de 15 mil km de distância um do outro.

Compreendemos que a expressão sonora permite uma vinculação afetiva por parte dos ouvintes que, de alguma maneira, participam dos ambientes nos quais os boletins foram criados e organizam os próprios ambientes nos quais ouvem os mesmos boletins radiofônicos.

Quando o som é decodificado pelo nosso cérebro, primeiro ele passa por regiões ligadas à emoção e à memória. Só depois ele é interpretado pela razão... Enquanto a imagem visual dá possibilidades restritas, com a informação já mastigada pelos recursos visuais, o som da voz, da trilha musical, dos efeitos sonoros etc., excitam mais a imaginação (ALBANO, 2020).

A vivência da audição, um dos primeiros sentidos a se manifestar nos humanos, ainda quando no ventre materno, possibilita o acesso a regiões do cérebro ligadas à

\footnotetext{
${ }^{5}$ Disponível em: <https://tab.uol.com.br/noticias/redacao/2020/09/16/por-que-estamos-ouvindo-cadavez-mais-radios-e-podcasts.htm>. Acesso em: 20 set. 2020.
} 


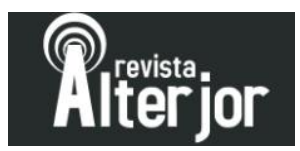

memória e às emoções, e também, estimula a imaginação com a criação de imagens sonoras.

\section{Etnografia, comunicação e cultura}

As complementariedades entre a comunicação e a etnografia, ainda que de maneira tímida e embrionária, começaram a tomar corpo e rumo a partir das observações e estudos de Bronislaw Malinowski (1884-1942) com habitantes da Papua Nova Guiné, um arquipélago encravado nos mares do Pacífico Sul. Malinowski, de raízes polonesas, começou a transformar seu fascínio por terras ainda pouco conhecidas e sem escrita, no início do século XX, em ciência a partir de 1910, quando iniciou seus estudos sociais na London School of Economics.

Antes desta incursão inglesa, já havia se graduado em Ciências Exatas pela Universidade de Cracóvia (Polônia) e feito sua pós-graduação na Universidade de Leipzig (Alemanha) em etnologia, área dedicada aos estudos dos povos do, conforme denominação hoje em desuso, novo e do velho mundo. Irrequieto e vagante por natureza, o jovem pesquisador quis romper com os métodos que eram utilizados pelos etnólogos da época, que praticavam uma visão de mundo dentro de casa, no escritório da universidade ou no museu repleto de itens trazidos de locais “exóticos”. Ives Winkin (1998) reconstitui como se desenvolviam os estudos dos pesquisadores que atuaram antes de Malinowski:

Enviam questionários etnográficos a viajantes, a missionários, a comerciantes, em suma, a todos que vão, por exemplo, à África ou à Ásia. Pedem-lhes que respondam às perguntas e comprem, se não roubem, tudo o que possam encontrar (...) Todos os objetos são bons para rechear os museus de etnografia (...) (WINKIN, 1998, p.130).

Malinowski então ruma a uma faixa de terra colonizada pela Inglaterra, na porção sul da Papua Nova Guiné, e passa a fazer um trabalho de campo com os Mailu e os Trobiland, que viria a gerar o livro Os Argonautas do Pacífico Ocidental (1922). Nesta obra, ele procura "captar o ponto de vista do indígena (...) compreender sua visão de mundo" (MALINOWSKI apud WINKIN, 1998, p.130). Os meses de imersão junto aos povos ajudaram o aventureiro europeu a compreender que um período extenso de 


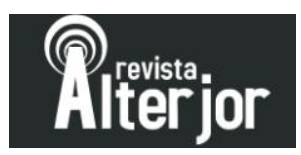

estudo pode ajudar a conhecer uma sociedade específica e perceber o significado de sua lógica cultural (MATEUS,2015, p.85).

O bom é que neste florescer da etnografia, da década de 1920 em diante, é que Malinowski não estava sozinho em sua atitude "rebelde" e influenciou, direta e indiretamente, pesquisas de campo em várias partes do mundo. $\mathrm{O}$ antropólogo inglês Gregory Bateson (1904-1980) teve experiências com tribos da Papua Nova Guiné e de Bali, uma das 13 mil ilhas que compõem a Indonésia e, a partir de seu caderno de anotações, produziu o livro Naven (1927). Neste mesmo ano, só que muito longe das paisagens deslumbrantes da Micronésia e seu caldeirão de povos e costumes, Mário de Andrade (1893-1945) revira os intestinos verdes do Brasil em uma longa viagem pelo Pará, Amazonas e partes do Peru e da Bolívia, viagem esta fundamental para a publicação de O Turista Aprendiz (1927). E este "olhar para dentro" ou endótico, exercitado por Andrade, viria a marcar, entre outros fatores, a tônica do segundo momento de virada da etnografia em sua caminhada pelo século XX.

Nos anos 1930, passando pela Segunda Guerra Mundial (1939-1945) até o início dos anos 1950, pensadores estadunidenses, como Lloyd Warner (1898-1970), Ray Birdwhistell (1918-1994), vão questionar se o trabalho de um etnógrafo deve ser voltado a estudar culturas e povos distantes de sua realidade, ou que metodologias podem e devem ser utilizadas para observar o que se passa ao redor do próprio país, no caso os EUA. Warner, após vivências com aborígenes da Austrália, passa a aplicar seu meticuloso trabalho de observação de micro sociedades em cidades minúsculas dos estados de Illinois e Massachusetts (WINKIN, 1998, p.130).

Birdwhistell também vai se voltar à observação dos costumes estadunidenses a partir de adolescentes do Kentucky. Foi influenciado pela Escola de Chicago (criada em 1892), um dos centros de referência da antropologia social no país, e fez parte do chamado Colégio Invisível, denominação utilizada por Yves Winkin para se referir ao intercâmbio de ideias, estudantes e professores ao redor da Escola de Palo Alto (Califórnia).

A multiplicidade de possibilidades gerada pela etnografia fez com que ela, no início dos anos 1960, encontrasse de forma seminal outra ciência humana conhecida por sua elasticidade de diálogos com outras frentes: a comunicação. O termo Etnografia da 


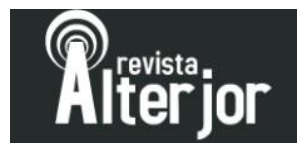

Comunicação surgiu a partir dos estudos do sociólogo norte-americano Dell Heymes (1927-2009) que, em 1964, o utilizou pela primeira vez. Segundo Heymes, a Etnografia

da Comunicação trata da relação entre a linguagem e a sociedade. Ou como propõe o antropólogo belga Etienne Samain na abertura de A nova comunicação: Da teoria ao trabalho de campo (1998), de que a antropologia e a comunicação se dão muito bem, mas se comunicam muito mal, e de que nenhum antropólogo contestará o fato de que a comunicação está no âmago de seu ofício (SAMAIN, 1998).

Neste trabalho consideramos que a comunicação acontece em ambientes culturais específicos e envolve não apenas o uso de signos verbais. Compreendemos que a observação dos processos de comunicação em perspectiva etnográfica implica a atenção ao conjunto de outras expressões gestuais que marcam as relações sociais, as emoções e as identidades sociais em jogo (MATEUS, 2015, p. 87).

A introdução das técnicas etnográficas nos estudos da cultura e da comunicação, incluindo o campo esportivo, influenciou a criação de escolas ao redor do mundo, como a Americana, que introduziu a Teoria da Cultura, no qual as expressões de todas as sociedades humanas são aglutinadas, desde aspectos materiais até o universo simbólico que as rodeia (ORTIZ, 2002, p. 21).

Na Europa, a Universidade Livre de Berlim se tornaria, ao longo dos séculos XX e XXI, uma das maiores expoentes deste campo. Por meio do Berliner Modell, os pensadores alemães desenvolveram uma nova perspectiva no estudo das relações entre a comunicação e a cultura. Teóricos como Dietmar Kamper (1936-2001), GunterGebauer, Christoph Wulf e Hans Ulrich Gumbrecht passaram a introduzir a questão do corpo, inclusive na ótica esportiva, como um elemento de construção social, disciplinar, filosófico e principalmente, mimético, no sentido de que cada homem de alguma forma copia, ou atualiza de forma criativa, aquilo que seus antepassados criaram como uma segunda realidade (a simbólica) e confere a ela toda autonomia para que ela dite seu destino (BAITELLO, 2012, p. 17).

Também é muito importante destacar a fundamental importância de outro expoente da Universidade Livre de Berlim e de origem não-alemã: o semioticista tcheco Ivan Bystrina (1924-2004). Bystrina, que fugira de Praga em 1968, após a chamada 


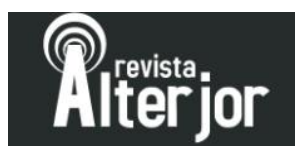

Primavera de Praga, recebeu convite de Harry Pross (1923-2010), então diretor da Faculdade de Ciências de Comunicação da Universidade de Berlim, para lecionar na cidade alemã. Lá, o tcheco pode construir as bases do que viria a ser conhecida por Semiótica da Cultura, um tipo de semiótica muito própria, voltada a investigar os textos e raízes culturais (o

jogo seria uma das quatro raízes da cultura), e que se distanciou dos modelos já existentes, como os estudos de semiótica desenvolvidos nos Estados Unidos. A questão do jogo como uma das raízes da cultura (HUIZINGA, 1998,CAILLOIS, 1990, BYSTRINA, 1995) começa a perder espaço nos estudos das ciências humanas com o surgimento de uma concepção de esporte mais interessada nos aspectos profissionais e econômicos, a partir dos anos 1990, como a evolução das transmissões midiáticas, a arenização dos estádios para atender os megaeventos esportivos e o marketing, por exemplo. Para sobreviver nesse campo minado e truncado, a experiência etnográfica passa a jogar um papel estratégico quando entra como uma postura metodológica para compreensão das raízes culturais da construção simbólica dos megaeventos esportivos e algumas de suas variantes, como criação das comunidades imaginárias das torcidas e o uso de textos culturais nos processos de comunicação. Tais elementos passam a ser vistos, sob esta ótica, como um fenômeno de estudo muito rico e desafiante, tanto para pesquisas acadêmicas quanto para o exercício do jornalismo, como veremos no próximo tópico.

\section{As mil faces da Rússia}

Além das pesquisas sobre os conceitos de ambiente, etnografia e cultura, para se compreender e conseguir traduzir em uma cobertura jornalística além da epiderme do megaevento russo realizado em 2018, foi preciso mergulhar nas raízes da cultura deste país-continente, com 8,5 milhões de $\mathrm{km}^{2}, 100$ etnias e 200 idiomas diferentes, além de uma história milenar e repleto de complexidades e nuances. Para que isso fosse possível a elaboração do Boletim da Copa foi marcada pelo cultivo de uma atitude etnográfica (CANEVACCI; 1995 e MENEZES; PADOVEZ, 2018) também conhecida como “observação participante” (PEIRANO, 1995; MAGNANI, 2009; MATEUS, 2015) de um fenômeno. 


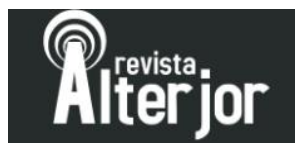

Durante a estadia em terras russas, busquei a todo tempo aprofundar a atitude etnográfica durante as andanças pelas cidades-sede da Copa do Mundo, com o objetivo de colocar em prática todo o conhecimento que havia cultivado no mestrado sobre a cultura russa. Assim, foi possível fazer uma imersão no país e a cada quilômetro rodado, construir boletins radiofônicos que trouxessem informações e curiosidades pouco conhecidas sobre a Rússia para os ouvintes brasileiros. Além de aspectos relacionados ao torneio, como os jogos que cada cidade que passei receberia, busquei trazer ao ouvinte pontos alternativos de cada uma delas, como as visitas à casa de veraneio (Datcha) que Josef Stalin (1878-1953) possuía em Sochi, e ao Museu da Guarda dos Cossacos, em Rostov-on-Don. Procurei também transformar em experiências radiofônicas aos ouvintes do boletim uma ida ao circo e ao cemitério da máfia russa, ambos em Ecaterimburgo, assim como ao apartamento museu do escritor Fiodor Dostoievski (1821-1881) em São Petersburgo, local onde ele escreveu Os Irmãos Karamazov, seu último livro e obraprima.

Outro artifício para se compartilhar o clima de cor local da Rússia por meio da voz e da paisagem sonora foi o uso da música tema da Copa, Live it Up (Nick Jam feat. Will Smith \& Era Strefi), como tema de abertura e de ambiente nos 30 boletins produzidos durante a cobertura do megaevento esportivo. Também foram utilizadas palavras presentes no idioma russo para fazer com que o ouvinte fosse transportado para dentro dos boletins, e por meio de uma vivência sonora, se sentisse dentro do país-sede do torneio e aprendesse um pouco mais sobre a cultura local, como давай давай Бразилия (vamos, vamos Brasil!) е пока-пока (tchau-tchau). Abaixo, trago como exemplo um trecho do episódio do dia 12 de junho, gravado a partir de Rostov-on-Don, palco da estreia do Brasil, diante da Suíça. Ao invés de falar sobre a partida, já fartamente noticiada pelos veículos de comunicação brasileiros, me dediquei a contar porque a cidade no sul da Rússia recebeu o nada lisonjeiro apelido de "cidade da morte". O som ambiente traz os movimentos do trem que me levavam deste o centro até a próxima parada, em Volgogrado.

Davai, davai, Brasilia. 


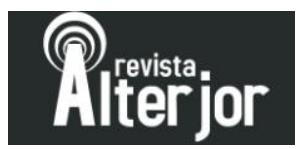

Olá amigo da rádio Gazeta AM. Como você já sabe, meu nome é Elcio Padovez e eu vou ser o correspondente da rádio aqui na Rússia. Hoje, estou a caminho de Volgogrado, ou como os russos dizem, Волгоград. É a terceira parada deste grande tour pela Rússia para cobrir a Copa do Mundo aqui na Rádio Gazeta AM. E como eu havia dito no boletim anterior, vou contar duas histórias muito interessantes. Uma bem macabra e a outra bastante histórica. E eu vou fazer isso a partir do trem, nesta viagem que dura $473 \mathrm{~km}$, mais ou menos 12 horas. É um trem lento, estilo soviético, um barulho bem gostoso para dormir. Aquele barulho do vagão passando pelos trilhos, bem devagar. A Rússia é toda coberta pelo sistema ferroviário, mas nem sempre é o sistema mais rápido. Mas é muito eficiente, posso garantir.

A primeira história, bem macabra. E você não precisa se preocupar porque ela está sob controle. Rostov é conhecida como a "cidade da morte". Mas este apelido, que nenhuma cidade gostaria de ter, foi dada a ela a partir dos anos 1980. Rostov, que tem mais de um milhão de habitantes, teve muitos problemas com traficantes de drogas e muitos problemas com serial killers. É a cidade que mais registrou assassinos deste tipo entre 1980, 1990 e o início dos anos 2000. E a lista é extensa. Vou trazer para você aqui uma das histórias, a do Andrei Chikatilo, um ucraniano que entre 1978 e 1990, matou apenas 53 pessoas. Ele ganhou um apelido bem bacana e singelo, o de "o açougueiro de Rostov". Tem também o Anatoly Slivko, que matou e esquartejou sete escoteiros e que segundo seu depoimento, ele presenciou o atropelamento de um escoteiro e ejaculou na hora.

Esta é uma cidade bem industrial e repleta de tipos perturbados. Um deles foi chamado de "besta de Tangarov", que após estuprar e matar suas vítimas, colocava neles uma meia calça como sua assinatura. Houve também casos de seriais killers necrófilos, que gostavam de transar com os cadáveres e outros tipos de sadismo (...) Rostov se preocupou tanto com isso que eles possuem até hoje uma polícia especializada em seriais killers, para poder identificar, rastrear e prender essas pessoas antes que elas cometam seus crimes. É uma cidade que mudou muito e tem outro perfil hoje. Então você pode vir tranquilo assistir ao jogo do Brasil. Toda essa má fama está sob controle e Rostov vai virar uma grande atração turística para quem vier acompanhar um dos cinco jogos que ela vai receber durante a Copa do Mundo (... $)^{6}$.

\section{Considerações Finais}

\footnotetext{
${ }^{6}$ Boletim disponível em: <http://www.radiogazetaonline.com.br/no-clima-da-copa/>. Acesso em: 20 set. 2020 .
} 


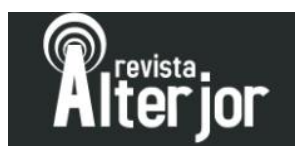

O mundo contemporâneo tem trazido cada vez mais desafios ao mercado de comunicação, como a queda na publicidade de anunciantes, cortes expressivos de profissionais nas redações, além da automatização da edição de textos e a diminuição do tempo para a apuração de novas histórias. Com a declaração do estado de pandemia devido ao novo coronavírus, feito pela Organização Mundial de Saúde (OMS) em março de 2020, o desafio aumentou. Ao mesmo tempo, nota-se a abertura de espaços e crescimento de produtos jornalísticos em paralelo às mídias tradicionais, como os podcasts, que tem registrado crescimento expressivo de 2018 em diante. Em meio a todo este cenário, um veículo de comunicação segue em alta, mesmo que já tenha passado dos 100 anos: o rádio, que é consumido pelo público brasileiro tanto de forma analógica quanto digital, e tem se mostrado um meio que se fortalece e se reinventa a cada crise.

Segundo dados do Ibope em 2020, $86 \%$ da população brasileira que consome algum tipo de mídia é impactada pelo rádio e deste montante, 59\% dos brasileiros ouvem rádio apenas de forma online. Segundo a professora Nair Prata (Universidade Federal de Ouro Preto - UFOP) em entrevista ao UOL Ecoa:

É interessante ver que mesmo numa sociedade hiperconectada e multiplataforma, diante das epidemias, catástrofes e grandes calamidades, o rádio é reconvocado ao protagonismo, dadas as suas características como dispositivo simples, barato, tradicional e de intensa capilaridade, chegando a lugares onde não é possível se pensar em internet (UOL Ecoa, 2020) ${ }^{7}$.

E não só o rádio tradicional tem crescido no Brasil. O mercado de podcasts aponta números promissores. Segundo levantamento feito pela empresa Deezer, 2019 registrou um crescimento de $67 \%$ no consumo desta mídia sonora no país ${ }^{8}$.

Também se faz necessário defender que o profissional de comunicação possa desenvolver novas habilidades e consiga desenvolver seu trabalho dentro um leque de

\footnotetext{
${ }^{7}$ Disponível em: <https://bit.ly/3ktronM.>. Acesso em: 20 set. 2020.

${ }^{8}$ O levantamento da Deezer foi feito em julho de 2020 e consolidou dados de ouvintes de podcasts de plataformas como o Spotify, Apple e Google Podcasts, e também, de aplicativos especializados na organização e distribuição deste tipo de conteúdo. Disponível em:
} <https://www.uol.com.br/tilt/noticias/redacao/2019/10/21/impulsionado-por-streaming-consumo-depodcast-cresce-67-no-brasil-em-2019.http.> Acesso em: 20 set. 2020. 


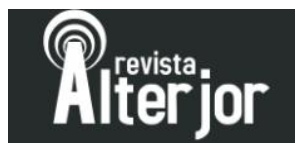

opções de meios, seja ele sonoro, escrito e imagético. Este comunicador multiplataforma, ao receber o desafio de cobrir um evento de grandes proporções, como uma Copa do Mundo ou uma pandemia, precisa desenvolver um trabalho de imersão prévia no fenômeno de análise. Isso vale tanto quanto o pesquisador acadêmico, que deve buscar compreender as raízes culturais e sociais desses megaeventos contemporâneos. No caso do esporte, eles têm sido cada vez mais complexos e simbolicamente construídos entre a tradição dos países ou cidades-sede e a estrutura globalizante e homogeneizadora de entidades como a Fifa e o COI. A cultura, como ambiente que envolve os processos de comunicação na contemporaneidade, atrai por sua complexidade e capacidade de abarcar num mesmo terreno a história, língua, religião, poder, geografia e geopolítica, num jogo dinâmico e repleto de carga simbólica.

No entanto, também é preciso ressaltar que o desenvolvimento da postura etnográfica, uma das alternativas para ser utilizada tanto por pesquisadores quanto por profissionais de comunicação, demanda tempo e paciência, pois ela acontece no tempo lento das observações vivenciais. Recomenda-se, como primeiro passo, ter formação bibliográfica sobre o fenômeno a ser estudado, antes de se "descer" ao trabalho de campo.

A vantagem dele, no caso da Copa do Mundo e das Olimpíadas, é que os dois megaeventos esportivos ocorrem a cada quatro anos, um tempo mais espaçado se comparado a outros eventos esportivos de menor escala, como a Liga dos Campeões e o Campeonato Brasileiro, realizados todos os anos.

Este alargamento de horizonte pelo estudo e observação atenta de diferentes ambientes culturais amplia as possibilidades de, no caso do campo da comunicação, gerar produtos e materiais mais "exclusivos" para os veículos que investirem neles, o que pode atrair maior interesse, audiência e credibilidade junto ao público, e também, oportunidades de aumento de anúncios publicitários. Já para o campo acadêmico, é possível apontar a geração de novas pesquisas e produções mais enriquecedoras e plurais a partir da experiência etnográfica.

A vantagem dele, no caso da Copa do Mundo e das Olimpíadas, é que os dois megaeventos esportivos ocorrem a cada quatro anos, um tempo mais espaçado se 


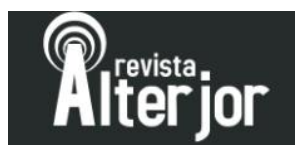

comparado a outros eventos esportivos de menor escala, como a Liga dos Campeões e o Campeonato Brasileiro, realizados todos os anos.

Este alargamento de horizonte pelo estudo e observação atenta de diferentes ambientes culturais amplia as possibilidades de, no caso do campo da comunicação, gerar produtos e materiais mais "exclusivos" para os veículos que investirem neles, o que pode atrair maior interesse, audiência e credibilidade junto ao público, e também, oportunidades de aumento de anúncios publicitários. Já para o campo acadêmico, é possível apontar a geração de novas pesquisas e produções mais enriquecedoras e plurais a partir da experiência etnográfica.

\section{Referências}

BAITELLO Jr., Norval. A produção do conhecimento no ambiente digital. VI Simpósio de Comunicação. São Paulo: FAPCOM, 2013. Disponível em:

<https://www.youtube.com/watch?v=Hr-HDQv_eHs>. Acesso em: 5 set. 2020.

GEBAUER, Günter; WULF, Christoph. O Jogo no Esporte. In: Mimese na cultura. Agir

Social. Rituais e Jogos. Produções Estéticas. São Paulo: Annablume, 2004, p.160-166.

MAGNANI, José Guilherme Cantor. Etnografia como prática e experiência. Horizontes Antropológicos, São Paulo, v. 15, n.32, p. 129-156, 2009.

MATEUS, Samuel. A etnografia da comunicação. ANTROPOlógicas, Lisboa, n.13, 2015.

MENEZES, Eugenio; PADOVEZ, Elcio. A etnografia como método de observação e cobertura de megaeventos esportivos. In: Communicare, São Paulo, v. 18., n. 1, p. 55-64, 2018.

MENEZES, José Eugenio de O. Cultura do ouvir, vínculos e ambientes comunicacionais. In: Cultura do Ouvir e Ecologia da Comunicação. São Paulo: UNI, 2016, p. 98-106. Disponível em: <https://casperlibero.edu.br/mestrado/livros--mestrado/>. Acesso em: 25 ago. 2017.

ORTIZ, Renato. As ciências sociais e a cultura. Tempo Social, São Paulo, v.14, n. 1, p. 19-32, 2002.

PADOVEZ, Elcio. Os símbolos na construção da Copa do Mundo da Rússia 2018.

Dissertação de Mestrado. São Paulo: Faculdade Cásper Líbero, 2018.

RÁDIOGAZETA ONLINE. No Clima da Copa. Disponível em: <http://www.radiogazetaonline.com.br/no-clima-da-copa/>. Acesso em: 9 jul. 2020.

UOL. Onda persistente: Centenário, rádio vira protagonista em catástrofes e viabiliza aulas onde conexão não chega durante pandemia. Disponível em: $<$ https://www.uol.com.br/ecoa/reportagens- especiais/centenario-radio-viabiliza-aulas-ondeconexao-nao-chega-durante- pandemia/?fbclid=IwAR0X1eovyUr8aJ0k7qcPYfOtb23C0jZaxuKtVZwAUnRN2KsyYDyOh564ug. >. Acesso em: 2 set. 2020. 


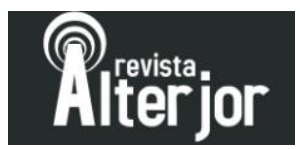

UOL. Graças a streaming, consumo de podcasts cresce a galope no Brasil este ano.

Disponível em: <https://www.uol.com.br/tilt/noticias/redacao/2019/10/21/impulsionado-porstreaming-consumo-de-podcast-cresce-67-no-brasil-em-2019.htm>. Acesso em: 21 set. 2020.

UOL. Fala que eu te escuto: porque ouvimos cada vez mais rádio e podcasts? Disponível em: <https://tab.uol.com.br/noticias/redacao/2020/09/16/por-que-estamos-ouvindo-cada-vezmais-radios-e- podcasts.htm>. Acesso em: 21 set. 2020.

WATSUJI, Tetsuro. Antropologia del paisaje. Climas, Culturas y religiones. Salamanca: Ediciones Sígueme, 2006.

WINKIN, Yves. A nova comunicação: da teoria ao trabalho de campo. Etienne Samain (Org.). Campinas: Papirus, 1998. 